\title{
Re: AORTODUODENAL FISTULA THREE YEARS AFTER AORTOBIFEMORAL BYPASS: CASE REPORT AND LITERATURE REVIEW
}

\author{
Ivan Cvjetko
}

Department of Vascular Surgery, Merkur University Hospital, Zagreb, Croatia

Dear Editor,

Marolt et al. have presented a very interesting case of aortoduodenal fistula and its successful treatment ${ }^{1}$. I have read the article with great interest since it is one of the worst complications that vascular surgeon may face.

We had a case of infected abscess and leakage in the thoracic aorta successfully treated with endovascular graft (TEVAR). Our approach for abdominal aorta is graft removal and axillobifemoral bypass. I completely agree with the authors that it is necessary to cover duodenal lesion with omental flap, although we do not perform excision of the duodenal/intestinal wall.

So far, we had no thrombosis of the axillofemoral bypass and it is remarkable to see sufficient inflow of the blood through narrow bypass (usually PTFE 6 $\mathrm{mm}$ ) to both legs. In order to prevent thrombosis, we always perform distal anastomosis above deep femoral artery or directly to the bifurcation of the common femoral artery. Outflow through deep femoral artery is usually able to keep the flow through axillofemoral bypass running. If not, bypass distal to the occlusion of the superficial artery (or popliteal artery) should be performed.
The European Society for Vascular Surgery (ESVS) has issued clinical practice guidelines for the management of abdominal aortic aneurysms ${ }^{2}$. Unstable patients might benefit from stent graft (Level 4, Recommendation $\mathrm{C}$ ); stable patients with aortoenteric fistula should receive staged procedure with extra-anatomic bypass first (Level 2c, Recommendation B); and finally stable patients without aortoenteric fistula (patients that do not have direct communication between proximal anastomosis and bowel but infected paraanastomotic sinus) should receive in situ revascularization using autogenous superficial femoral vein or aortoiliac allograft (Level 2c, Recommendation C)2.

\section{References}

1. Marolt U, Potrc S, Bergauer A, Arslani N, Papes D. Aortoduodenal fistula three years after aortobifemoral bypass: case report and literature review. Acta Clin Croat. 2013;52:363-8.

2. Moll FL, Powell JT, Fraederich G, et al. Management of Abdominal Aortic Aneurysms Clinical Practice Guidelines of the European Society for Vascular Surgery. Eur J Vasc Endovasc Surg. 2011;41 Suppl 1:S32-4. doi: 10.1016/j.ejvs.2010.09.011

Correspondence to: Ivan Crjetko, $M D, P h D$, Department of Vascular Surgery, Merkur University Hospital, Zajčeva 19, HR-10000 Zagreb, Croatia

E-mail: ivancvjetko@yahoo.com

Received March 10, 2014, accepted May 12, 2015 